\title{
Dispersion of multi-walled carbon nanotubes in [BMIM]PF6 for electrochemical sensing of acetaminophen
}

\author{
Rayane N. Gomes \\ Camila P. Sousa \\ Paulo N.S. Casciano \\ Francisco Wirley P. Ribeiro \\ Simone Morais \\ Pedrode Lima-Neto \\ Adriana N. Correia
}

\section{Abstract}

The influence of functionalized multi-walled carbon nanotubes (fMWCNT) in the presence of 1-butyl-3-methylimidazolium hexafluorophosphate ([BMIM]PF6) in different ratios was investigated on the acetaminophen (ACOP) electrochemical determination. The electrochemical behavior of the ACOP exhibited a pair of well-defined redox peaks, suggesting that the reversibility of ACOP was significantly improved in comparison to irreversible oxidation peak on bare GCE. The redox process was controlled by adsorption, involves two electrons and the value of apparent rate constant $(\mathrm{ks})$ was equal to $14.7 \mathrm{~s}-1 \pm 3.6 \mathrm{~s}-1$. The analytical curves were obtained for concentrations of ACOP ranging from 0.3 to $3.0 \mu \mathrm{mol} L-1$. The values of the detection limit were calculated from SWV and found to be $6.73 \times 10-8 \mathrm{~mol} \mathrm{~L}-1$. The proposed electrochemical sensor exhibited good stability and reproducibility and was applied for ACOP determination in tablets $\left(\right.$ Tylenol $\AA^{\circledR}$ and Tylenol $(\AA D C)$ with satisfactory results.

\section{Keywords}

Paracetamol; 1-Butyl-3-methylimidazolium hexafluorophosphate; fMWCNT; Square-wave voltammetry; Electrochemical sensor

1. Introduction

Acetaminophen (N-acetyl-p-aminophenol, ACOP) is one of the most used pharmaceutical compounds in many countries. In most cases, ACOP is the first choice to be administered as analgesic and antipyretic drugs. As reported in the literature, the use of ACOP in excess leads to hepatotoxicity and nephrotoxicity cases [1,2]. Due to the harmful effect to human health, the development of analytical methods for its determination has increased [[3], [4], [5], [6], [7], [8], [9], [10], [11], [12], [13], [14], [15]]. As a result of the ACOP's ability to oxidize electrochemically on the surface of the electrode, the number of publications related to ACOP electrochemical detection has been increased over the last years [3]. It is common knowledge that various configurations of modified electrodes can be constructed. Therefore, electrochemical sensing has attracted much interest in the field of analytical chemistry.

Room temperature ionic liquids (RTIL) can be defined as liquid electrolytes made entirely of ions which have melting points below $100{ }^{\circ} \mathrm{C}$ [16]. The RTIL structure typically consists of a bulky and large organic cation and an organic/inorganic anion, wherein the difference in size of cations and anions does not enable the formation of an ionic lattice; instead, ions are typically disorganized, which results in the salts remaining liquid at room temperature. The unique physicochemical properties of RTIL have been highly utilized in Electrochemistry, commonly in the form of RTIL-carbon nanomaterial hybrids. The intrinsic conductivity of RTIL makes them useful in electrochemical studies for detection of different types of compounds such as pharmaceuticals, endocrine disrupters, neurotransmitters, pesticides and others [17].

The combination of RTIL and carbon nanotubes in the construction of modified electrodes can provide unique advantages due to the synergistic effect and significant enhancement for numerous electrochemical applications. The excellent electrical conductivity, need for high surface area, catalytic activity and high sensitivity is fundamental to the extensive usefulness and numerous applications of RTIL [18]. Yan et al. [19] reported a voltammetric procedure for uric acid determination using a multi-walled carbon nanotube-ionic liquid paste coated glassy carbon electrode (GCE), with the use of the IL improved the electrocatalytic properties of the electrode surface for uric acid detection. Tao et al. [20] reported a voltammetric procedure for estradiol determination using GCE modified with multi-walled carbon nanotubes (MWCNT) and the 1-butyl-3-methylimidazolium hexafluorophosphate ([BMIM]PF6). The proposed electrode afforded an electrocatalytic effect when compared with MWCNT/GCE for estradiol detection. This effect has been attributed to increased uniformity of the film on the GCE surface in the presence of the RTIL, the "cation-p" interactions with the RTIL and the high number of electroactive 
sites of MWCNT and the accumulation of the analyte molecule on the electrode surface from the hydrophobic ionic liquid-estradiol molecule interaction [20]. Similar results were observed for the determination of different molecules as endocrine disrupters [21], bisphenol A [22], dopamine [23] and pyrimethanil [24].

Although different sensors are described in the literature, many of these are examples of a carbon ionic liquid paste electrode, to obtain an electrode with high performance and optimum values of reproducibility and detection limits. On the other hand, it is not established that there is a direct correlation with the ratios of MWCNT and ionic liquid proportion and their performance as an electrochemical sensor.

Considering what has been described above, this study focused on the dispersion of functionalized multi-walled carbon nanotubes (fMWCNT) in the presence of [BMIM]PF6 on GCE in different ratios was used to develop a suitable sensor for the determination of ACOP in two different pharmaceutical formulations (Tylenol $\AA^{\circledR}$ and Tyleno| $\circledast D C$ ) applying a simple, accurate and low-cost sensitive electrochemical methodology.

2. Experimental

\subsection{Chemicals and reagents}

ACOP, Nafion ${ }^{8}$ (10 wt\% in H2O), [BMIM]PF6, multi-walled carbon nanotubes powder (MWCNT, 6-9 nm diameter, $5 \mu \mathrm{m}$ length) was obtained from Sigma Aldrich. All others reagents and solvents used in this study were analytical grade. ACOP tablets (Tylenol® and Tylenol $(\mathrm{D} D \mathrm{C}$ ) were purchased from Janssen-Cilag Farmacêutica Ltda (São Paulo, Brazil). All the solutions were prepared with water purified by Milli-Q System (Millipore Corp.). ACOP standard solution was prepared by dissolving an appropriate quantity in ultrapure water, which was then stored in a dark flask and kept in a refrigerator to prevent degradation.

\subsection{Apparatus}

Electrochemical measurements were performed on an Autolab PGSTAT 101 Metrohm-Eco Chemie controlled by a personal computer, using Nova software version 1.11.2. A conventional three-electrode system, which was composed of a bare or modified GCE (BASi, $3 \mathrm{~mm}$ diameter) as the working electrode, a Pt sheet as the auxiliary electrode and an $\mathrm{Ag}(\mathrm{s}) / \mathrm{AgCl}(\mathrm{s}) / \mathrm{Cl}-(\mathrm{aq})$ (saturated $\mathrm{KCl})$ as the reference electrode. When it was necessary, a Microanal $\mathrm{B} 474 \mathrm{pH}$ meter equipped with a $\mathrm{Ag} / \mathrm{AgCl} / 3.0 \mathrm{~mol} \mathrm{~L}-1 \mathrm{KCl}$ glass combined electrode was used to adjust the $\mathrm{pH}$ values by adding appropriate amounts of $1.0 \mathrm{~mol} \mathrm{~L}-1 \mathrm{NaOH}$ stock solution. The electrodes were cleaned in a Quimis model Q335D ultrasonic cleaner equipped with a heating bath. Surface characterization of the fMWCNT[BMIM]PF6/GCE and fMWCNT/GCE was acquired by field emission gun-scanning electron microscope (FEG-SEM) using a FEI-Quanta 450 FEG microscope. The zeta potential of the fMWCNT-[BMIM]PF6 was measured using a Malvern Zetasizer NS 3601 at $25^{\circ} \mathrm{C}$.

\subsection{Sensor preparation}

The MWCNT were functionalized by acid treatment with concentrated sulfuric acid and nitric acid (3:1 v/v) [25]. This mixture was under moderate magnetic stirring for $12 \mathrm{~h}$ at $26 \pm 1^{\circ} \mathrm{C}$. Then, the suspension was vacuum filtered, washed several times with ultrapure water until a pH 7.0 was achieved, and was then dried at $70^{\circ} \mathrm{C}$ for $12 \mathrm{~h}$. This strong acid treatment promotes the generation of functional groups, such as carboxyl, hydroxyl, quinone, nitro, and amino, on the surface of the MWCNT [26,27].

The composite material was produced by mixing different amounts of fMWCNT, [BMIM]PF6 and Nafion® dispersion. Several ratios of fMWCNT and [BMIM]PF6 were evaluated, namely, 1:0; 1:5; 1:10;1:20;1:30;1:40 and 0:1 (w/w). Typically, a dispersion containing fMWCNT, [BMIM]PF6 and Nafion $®$ were prepared by adding an appropriate mass of IL in $1.0 \mathrm{mg}$ of fMWCNT dispersed in $1.0 \mathrm{~mL}$ of dimethylformamide (DMF) containing $0.5 \%(\mathrm{w} / \mathrm{w})$ Nation $\AA^{8}$ in dimethylformamide (DMF). Next, the fMWCNT-[BMIM]PF6 dispersion was obtained by sonication for $5 \mathrm{~min}$.

GCE was polished with $3 \mu \mathrm{m}$ diamond paste, then washed with ultrapure water, immersed in ethanol and placed in an ultrasound bath for $5 \mathrm{~min}$. This last procedure was repeated with purified water. Finally, the surface of the GCE was dried by a stream of N2 (White 
Martins, Brazil). The modified with fMWCNT-[BMIM]PF6 suspension by dropping $1.5 \mu \mathrm{L}$ onto the GCE surface, and dried at $60{ }^{\circ} \mathrm{C}$ for $15 \mathrm{~min}$ in a homemade oven lamp. When not in use the modified electrode was stored in a desiccator at room temperature.

\subsection{Electrochemical experiments}

An electrochemical cell containing $10.0 \mathrm{~mL}$ of supporting electrolyte was used for electrochemical experiments. Between each experiment, the solution was stirred using magnetic stirrer for $3 \mathrm{~min}$, thus assuring the reproducibility of all the experiments. The buffer solutions using as supporting electrolytes were $0.1 \mathrm{~mol} \mathrm{~L}-1$ Mcllvaine buffer (prepared by mixture of $0.1 \mathrm{~mol} \mathrm{L-1}$ citric acid and $0.1 \mathrm{~mol} \mathrm{~L}-1$ sodium hydrogen phosphate in suitable amounts to obtain the desired pH), $0.1 \mathrm{~mol} \mathrm{~L}-1$ Sörensen buffer (prepared by mixture of $0.1 \mathrm{~mol} \mathrm{~L}-1$ sodium hydrogen phosphate and $0.1 \mathrm{~mol} L-1$ potassium dihydrogen phosphate), 0.1 mol L-1 potassium biphthalate (prepared by mixture of $0.1 \mathrm{~mol} \mathrm{~L}-1$ potassium biphthalate and $0.1 \mathrm{~mol} \mathrm{L-1}$ ), and $0.04 \mathrm{~mol} \mathrm{L-1}$ Britton-Robinson (BR) buffer (prepared by the mixture of $0.04 \mathrm{~mol} \mathrm{L-1}$ phosphoric acid, boric acid, and acetic acid and the $\mathrm{pH}$ was adjusted to the desired value by adding suitable amounts of $1.0 \mathrm{~mol} \mathrm{L-1} \mathrm{NaOH}$ stock solution. Cyclic voltammetry (CV) was used to obtain the electrooxidation results of the ACOP besides the adsorption character of the modified electrode. Square-wave voltammetry (SWV) was the electrochemical technique performed to detect and to quantify the ACOP. The optimization of the analytical procedure was carried out in response to a systematic study of experimental parameters which affect the responses, such as supporting electrolyte, $\mathrm{pH}$, pulse potential frequency (f), amplitude of the pulse $(\mathrm{a})$ and the height of the potential step $(\Delta \mathrm{Es})$. All parameters presented appropriately optimized with regard to the maximum value of the peak current, because their values exert influence on the high sensitivity of voltammetric analysis [28].

\subsection{Sample preparation}

Two pharmaceutical samples containing ACOP, Tylenol 8500 tablets, each tablet containing $500 \mathrm{mg}$ of ACOP, purified water, starch, pre-gelatinized starch, sodium starch glycolate, micro-fine cellulose magnesium stearate, hypromellose and Macrogol. Tylenolß DC tablets, each tablet containing $500 \mathrm{mg}$ of ACOP and $65 \mathrm{mg}$ of caffeine, corn starch, pre-gelatinized starch, sodium starch glycolate, micro-fine cellulose, FD\&C Yellow No. 6 aluminum lake, FD\&C Red No. 40 aluminum lake, titanium dioxide, magnesium stearate, hypromellose and Macrogol, were purchased from a local drugstore. A simple and fast sample preparation step [29] before aliquots of each working solution were directly transferred to the electrochemical cell and the respective voltammograms were recorded. The ACOP concentration of each sample was determined in triplicate using the analytical curve previously obtained. For the recoveries using UVVis technique, the procedure was adopted as described in Brazilian Pharmacopoeia to the quantification in tablets and oral solutions [30]. Tylenol $₫ D C$ and Tylenol $\circledast 500$ were prepared in $0.01 \mathrm{~mol} \mathrm{L-1} \mathrm{NaOH}$. Ten tablets were taken and weighed individually, and calculated the average mass and all solutions were prepared to a final concentration of $1.0 \times 10-3 \mathrm{~mol} \mathrm{L-1}$.

\section{Results and discussion}

\subsection{Morphological analysis of fMWCNT in the presence of [BMIM]PF6}

The SEM of bare GCE showed the profile characteristic from polishing procedure (Fig. 1A). The field emission scanning electron microscope was used to examine the morphologies of fMWCNT and fMWCNT-[BMIM]PF6. Fig. 1 shows field emission scanning electron microscope images for two different magnifications of GCE modified with different modifications. fMWCNT (B and D) and fMWCNT[BMIM]PF6 dispersion fMWCNT-[BMIM]PF6/GCE) (C and E). 


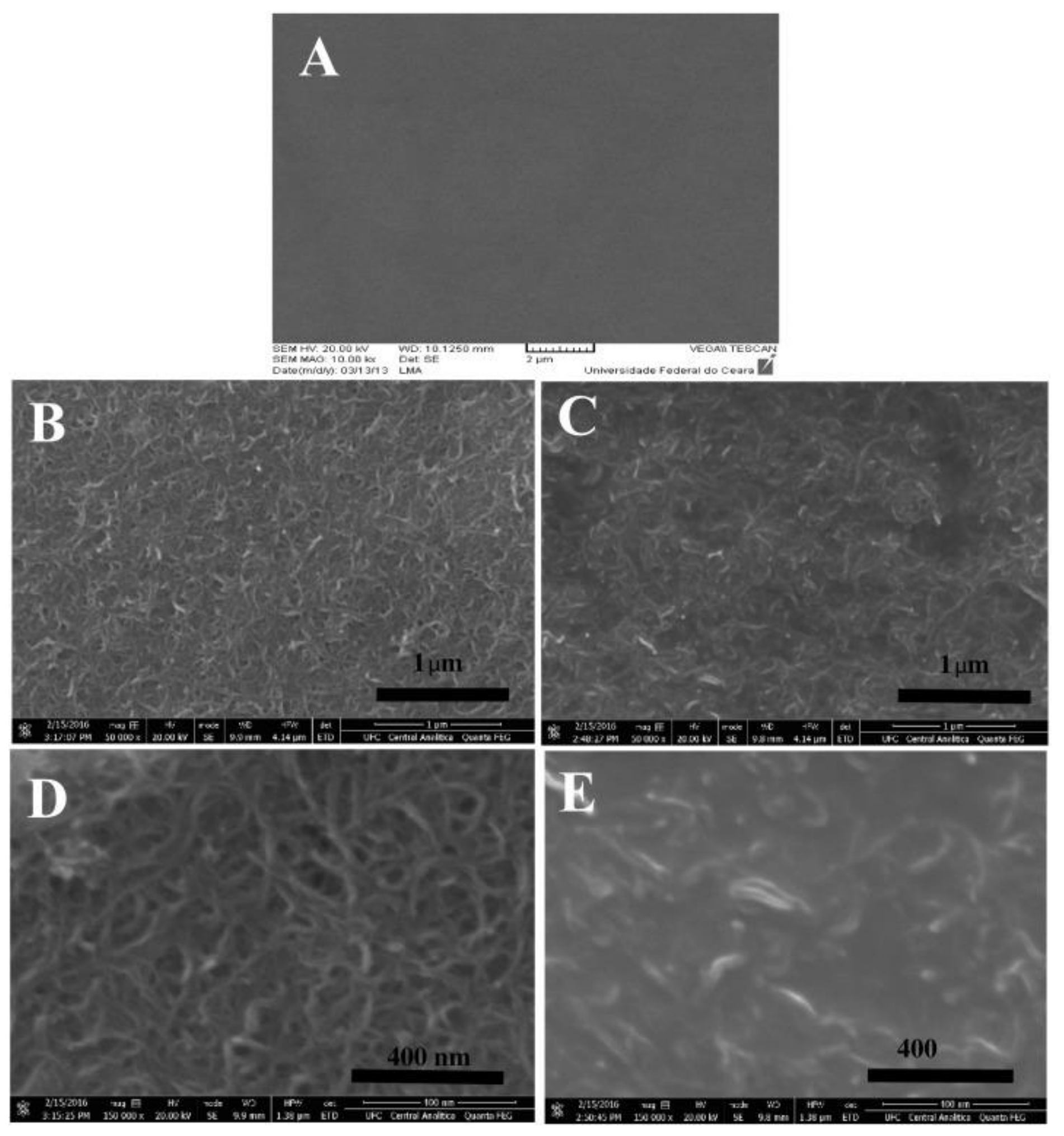

Fig. 1 - SEM image of bare GCE (A), FEG-SEM images obtained for GCE modified with fMWCNT (B, D) and fMWCNT-[BMIM]PF6 (1:5) (C, E).

The fMWCNT morphology was highly entangled with each other, forming a characteristic structure, (Fig. 1B, D), which could be allocated $\pi-\pi$ stacking interactions between fMWCNT, composing a structure firmly adherent to each other. However, the FEG-SEM recorded for the fMWCNT-[BMIM]PF6 (Fig. 1C and E) shows the formation of a material with gel aspect with fMWCNT wrapped by the RTIL architecture. The RTIL reduces the agglomeration of the nanotubes, which were more dispersed.

The [BMIM]PF6 used was composed of an imidazole ring and alkyl chain. The imidazole ring has a m-conjugated structure, and positive charge is located mainly in the imidazole ring, $\pi$-electrons and cations in [BMIM]PF6 could interact with $\pi$-electrons in fMWCNT. Additionally, the high surface energy of the fMWCNT was effectively appeased since they were surrounded by [BMIM] PF6 to $\pi-\pi$ stacking interactions and cation- $\pi$ interactions between RTIL and fMWCNT. Therefore, it could be assumed that [BMIM]PF6 played an important role in dispersing fMWCNT (Fig. 1C, E) [31,32].

In order to better characterize the [BMIM]PF6-fMWCNT was obtained the zeta potential for the fMWCNT surface functionalized with the [BMIM]PF6. The acid treatment of MWCNT produced carboxylic groups, which consequently makes the MWCNT surface negative [33,34]. The surface potential of [BMIM]PF6-fMWCNT became positive after modification with [BMIM]PF6 with value equal to $41.5 \pm 0.97 \mathrm{mV}$. The change in the potential is consequence of MWCNT surface functionalization $[35,36]$.

\subsection{Characterization of electrochemical behavior of the modified electrode}

Cyclic voltammetry (CV) was used to investigate the electrochemical behavior of a GCE, [BMIM]PF6/GCE, fMWCNT/GCE, Nafion®/GCE and fMWCNT-[BMIM]PF6/GCE in $1.0 \mathrm{mmol}[\mathrm{Fe}(\mathrm{CN}) 6] 3-/ 4-$ as electroactive indicator in $0.1 \mathrm{~mol} \mathrm{~L}-1 \mathrm{KCl}$ recording at a scan rate of $100 \mathrm{mV} \mathrm{s}-1$ (Fig. 2). 


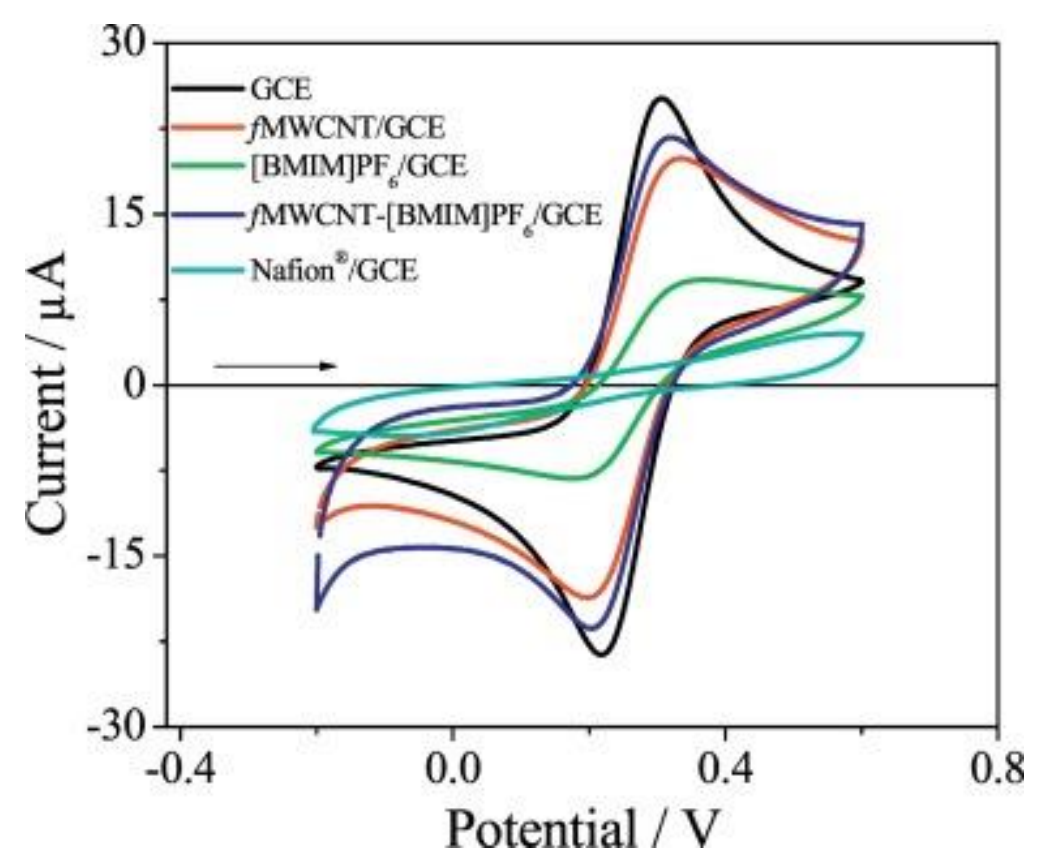

Fig. 2. Cyclic voltammograms for the GCE (black), fMWCNT/GCE (red), [BMIM]PF6/GCE (green), fMWCNT-[BMIM]PF6/GCE (1:10) (blue), and Nafion®/GCE (cyan) in 1.0 mmol $[\mathrm{Fe}(\mathrm{CN}) 6] 3-/ 4-$ in $0.1 \mathrm{~mol} \mathrm{~L}-1 \mathrm{KCl}$ at $100 \mathrm{mV} \mathrm{s}-1$. (For interpretation of the references to colour in this figure legend, the reader is referred to the web version of this article.)

A couple of reversible redox peaks of the probe could be observed on the modified electrodes, indicating a reversible electrochemical process. The current peak increased two times for the fMWCNT-[BMIM]PF6/GCE (1:10) when compared with the [BMIM]PF6/GCE and 1.1 times higher than the $\mathrm{MWCNT/GCE}$. The reason for these values may be attributed to the fact that fMWCNT could increase the effective surface area, and enhance the current signal of the electrode efficiently. However, as compared to unmodified GCE it is possible to verify that there was a decrease of 1.2 times the current value when compared with $\mathrm{MWWCNT}$-[BMIM]PF6/GCE.

The reason could be attributed to the negative charge of $\mathrm{Nafion} \AA$, which blocked the diffusion of ferrocyanide and ferricyanide towards the electrode surface, and thus completely hindering the electron and mass transfer. This was due to the electrostatic (negative charge) repulsive effects between Nafion $\AA$ and [Fe( $\mathrm{CN}) 6] 3-/ 4-[[37]$, [38], [39]], with no well-defined peak in cyclic voltammetry experiments for Nafion®/GCE there was defined peak as shown in Fig. 2.

The differences between anodic peak potential and cathodic peak potential (Epa-Epc) values, $85.4 \mathrm{mV}$ at $\mathrm{GCE}$ and $141.6 \mathrm{mV}$ at [BMIM]PF6/GCE, including $114.8 \mathrm{mV}$ at fMWCNT/GCE and $97.7 \mathrm{mV}$ at fMWCNT-[BMIM]PF6/GCE (1:10) for the redox process of $[\mathrm{Fe}(\mathrm{CN}) 6] 3-/ 4-$, indicated that the electrode surface with fMWCNT and [BMIM]PF6 improved the reversibility of the [Fe(CN)6]3-/4redox couple. These effects confirmed the large surface area and electrostatic interaction of fMWCNT and the affinity of the positively charged imidazolium cation for the negatively charge of the probe used.

\subsection{Factors influencing the determination of acetaminophen}

In order to achieve a maximum electrochemical response of the sensor, experimental parameters such as pH, supporting electrolyte and the mass ratio of [BMIM]PF6 and fMWCNT were optimized for the determination of ACOP. Firstly, the electrochemical behavior of $1.19 \times 10-5 \mathrm{~mol}$ L-1 ACOP at the fMWCNT-[BMIM]PF6/GCE $(1: 10)$ was evaluated by SWV with $\mathrm{f}=100 \mathrm{~s}-1, \mathrm{a}=50 \mathrm{mV}$ and $\Delta \mathrm{Es}=2 \mathrm{mV}$ in BR buffer with pH between 3.0 and 9.0 (data not showed). The BR buffer was selected for initial experiments because this is traditionally used in electroanalytical application [40,41]. A single well-defined process probably related to the oxidation of ACOP to the reactive metabolite, $\mathrm{N}$-acetyl-p-quinoneimine was observed at all $\mathrm{pH}$ in potential range from 0.2 to $0.8 \mathrm{~V}$ [[42], [43], [44], [45], [46]]. The potential of anodic electrochemical process shifted to more negative potentials with increasing solution $\mathrm{pH}$. Similar behavior was reported in the literature for ACOP detection using a carbon ionic liquid electrode [47] and using the glassy carbon electrode modified with 1butyl-3-methylimidazolium tetrafluoroborate and $\mathrm{TiO} 2$ nanoparticles [48]. The maximum peak current was clearly evidenced at $\mathrm{pH} 5.0$, which was selected as the optimized value.

In order to reach maximum sensitivity, the influence of IL amount in the fMWCNT-[BMIM]PF6 dispersion on the voltammetric response of the ACOP at fMWCNT-[BMIM]PF6/GCE was studied. The peak current for $1.19 \times 10-5 \mathrm{~mol} \mathrm{~L}-1 \mathrm{ACOP}$ in BR buffer $\mathrm{pH} 5$ was analyzed with GCE modified with dispersion in different proportions of [BMIM]PF6 and fMWCNT changed with different concentrations of [BMIM]PF6 (0.0 to $40 \mathrm{mg} \mathrm{mL-1}$ ), while the concentration of fMWCNT was fixed at $1 \mathrm{mg} \mathrm{mL}-1$, as can be seen in Fig. 3A where a peak current maximum was obtained. Through analysis of peak current of ACOP it was possible to conclude that the fMWCNT- 
[BMIM]PF6/GCE (1:5) exhibited a peak current which was 1.1 times higher than fMWCNT-[BMIM]PF6/GCE (1:10), 1.04 times higher than fMWCNT-[BMIM]PF6/GCE (1:30), 1.76 times higher than fMWCNT/GCE and exhibited a peak current which was 6\% lower than the value obtained for fMWCNT-[BMIM]PF6/GCE (1:20). Therefore, the dispersion of fMWCNT-[BMIM]PF6 containing $1 \mathrm{mg} \mathrm{mL}-1$ MWCNT and $5 \mathrm{mg} \mathrm{mL-1}$ [BMIM]PF6 was used to modify the GCE surface in the following electrochemical analysis.
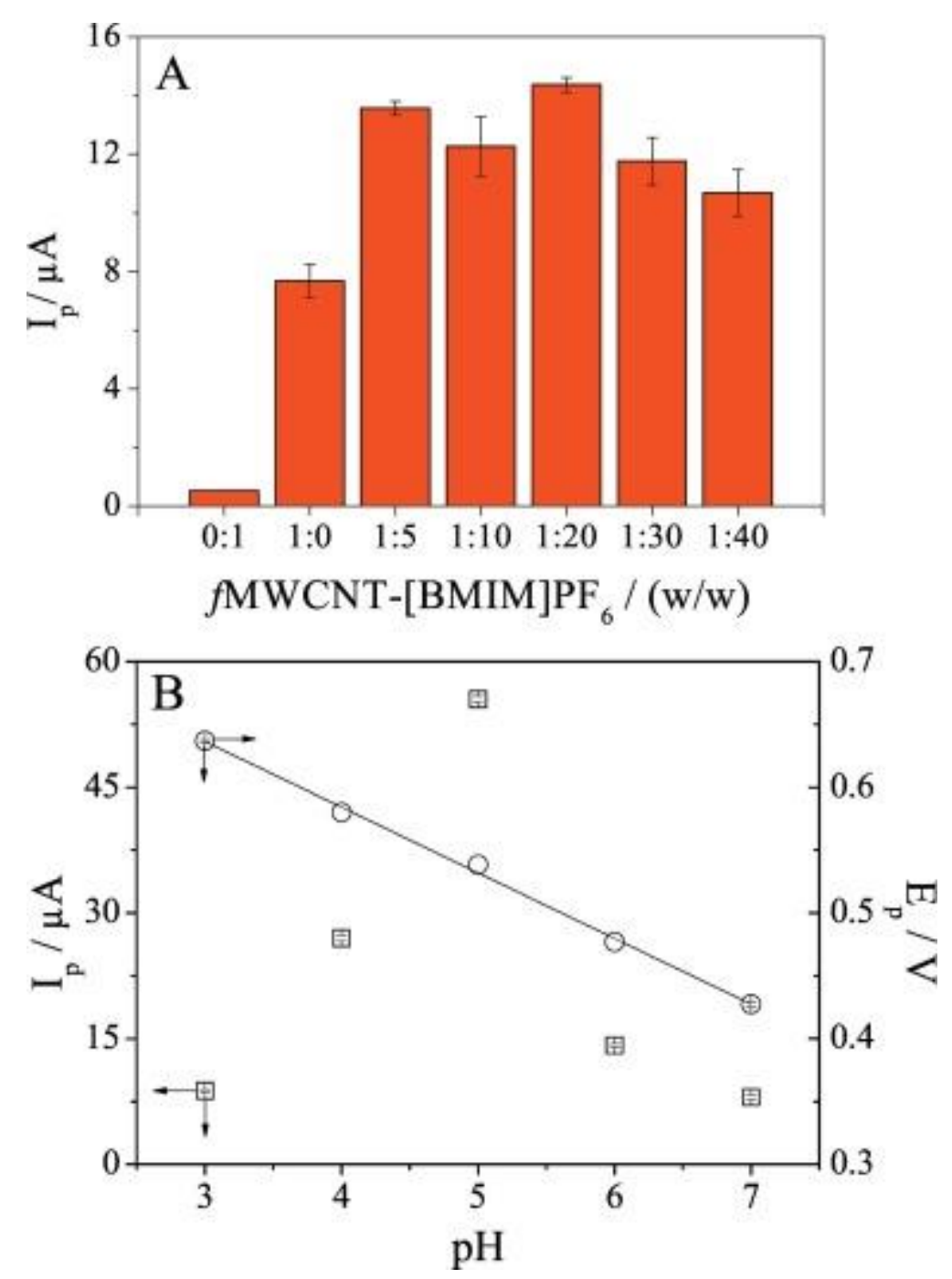

Fig. 3. (A) Effect of the mass ratio between fMWCNT and [BMIM]PF6 from the SWV for $1.19 \times 10-5$ mol L-1 ACOP in BR buffer pH 5.0, on fMWCNT-[BMIM]PF6/GCE; $f=100 \mathrm{~s}-1$; $a=50 \mathrm{mV}$ and $\triangle E s=2 \mathrm{mV}$. (B) Relationship between peak current (Ip), peak potential (Ep) and pH obtained from the SWV for 1.19 $\times 10-5 \mathrm{~mol} L-1 \mathrm{ACOP}$ in Mcllvaine buffer on fMWCNT[BMIM]PF6/GCE (1:5); $\mathrm{f}=100 \mathrm{~s}-1 ; \mathrm{a}=50 \mathrm{mV}$ and $\Delta \mathrm{Es}=2 \mathrm{mV}$.

In the presence of [BMIM]PF6, fMWCNT were dispersed by shear force. [BMIM] PF6 could keep the isolated fMWCNT rebinding together under the shielding effect of the $\pi-\pi$ stacking interaction between fMWCNT. In a high concentration of [BMIM]PF6, MWCNT could be wrapped up by [BMIM]PF6 minimizing the advantage of fMWCNT. Therefore, [BMIM]PF6 performed an irreplaceable role in the dispersion process MWCNT [49,50].

\subsubsection{Effect of the supporting electrolyte and $\mathrm{pH}$ values}

In order to optimize the supporting electrolyte, four different buffer solutions in $\mathrm{pH} 5.0$ were analyzed by SWV with $\mathrm{f}=100 \mathrm{~s}-1$, a $=50 \mathrm{mV}$ and $\Delta \mathrm{Es}=2 \mathrm{mV}$, with the values of peak current resulting in this order: biphthalate $(7.32 \mu \mathrm{A})<\mathrm{BR} \quad(18.73 \mu \mathrm{A})<\mathrm{Sörensen}$ $(39.77 \mu \mathrm{A})<$ Mcllvaine $(55.72 \mu \mathrm{A})$. Thus, Mcllvaine buffer was chosen as the optimized supporting electrolyte.

The effect of $\mathrm{pH}$ was evaluated for Mcllvaine buffer in $\mathrm{pH} 3.0$ to 7.0. It was observed that the peak potential shifted negatively with the increase of the $\mathrm{pH}$ value, as can be seen in Fig. 3B. The relationship between the potential $\mathrm{Ep}(\mathrm{V})$ and $\mathrm{pH}$ was directly investigated and a linear regression equation $\mathrm{Ep}(\mathrm{V})=-0.0522 \pm 7.7 \times 10-3 \mathrm{pH}+0.7932 \pm 1.5 \times 10-3, \mathrm{r}=0.9968$ was obtained. The calculated slope $(52.2 \mathrm{mV})$ was close to the theoretical one $(59 \mathrm{mV} \mathrm{pH}-1)$ for a classical Nernstian process with the participation of equal number of protons and electrons [51]. The similar result was obtained in the literature for ACOP detection for different modified electrodes described in the literature as MWCNT [52], Pd/graphene oxide [53], poly(4-vinylpyridine)/MWCNT [25], Fe3O4-poly(diallyldimethylammonium chloride-graphene/GCE [54] and ytrium hexacyanoferrate/reduced graphene oxide/GCE [55]. 
The electrochemical behavior of ACOP in different modified electrodes was assessed by CV in potential range from 0.2 to $0.8 \mathrm{~V}$. The voltammetric profiles for the bare GCE, [BMIM]PF6/GCE, fMWCNT/GCE and fMWCNT-[BMIM]PF6/GCE (1:5) in the presence of $1.19 \times 10-5 \mathrm{~mol} \mathrm{~L}-1$ of ACOP in Sörensen buffer pH5.0 at $10 \mathrm{mV} \mathrm{s}-1$ were shown in Fig. 4A.
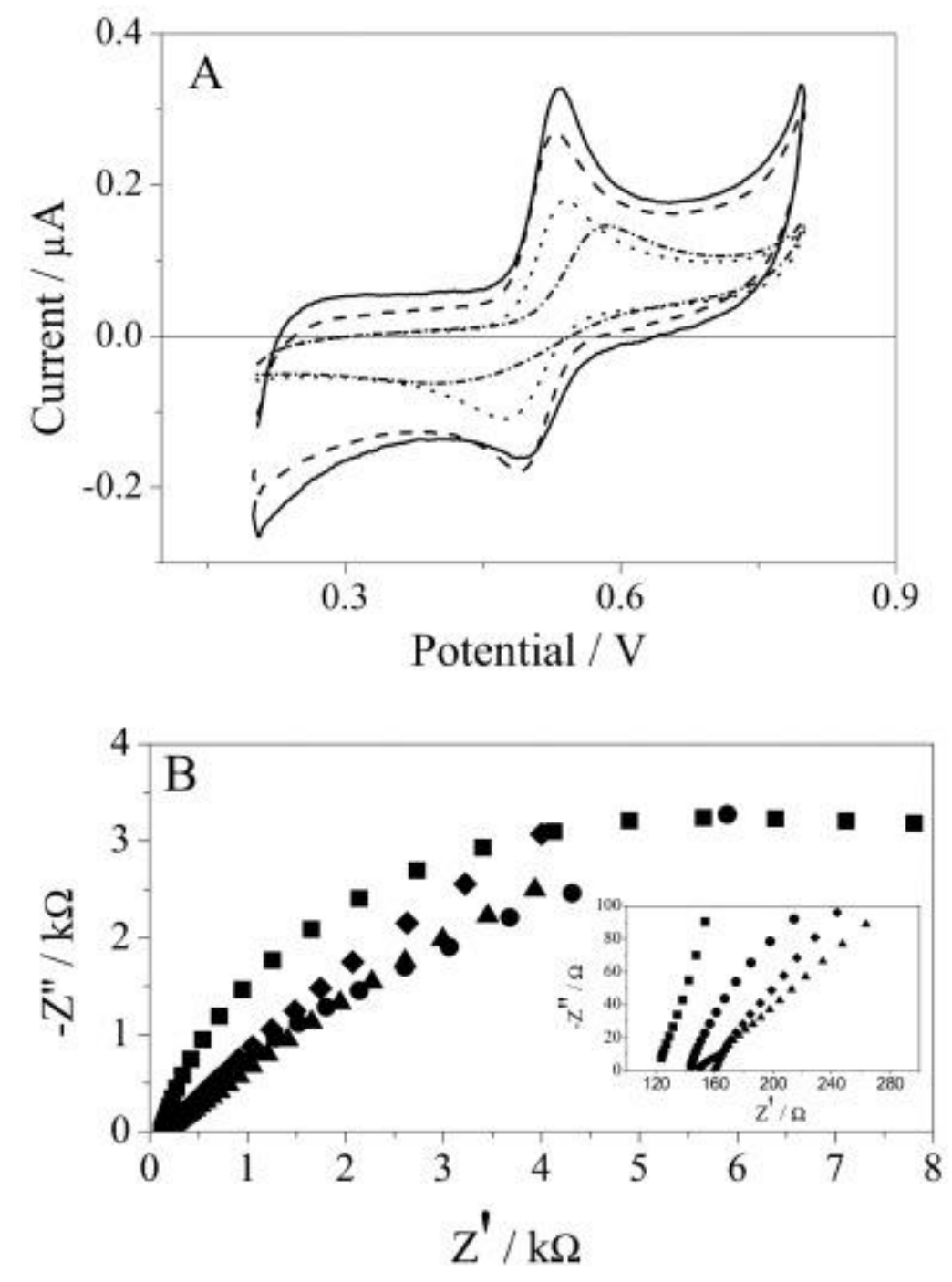

ig. 4. (A) Cyclic voltammograms for $1.19 \times 10-5 \mathrm{~mol} \mathrm{L-1} \mathrm{ACOP}$ in Mcllvaine buffer pH 5.0, scan rate $10 \mathrm{mV} \mathrm{s-1} \mathrm{on} \mathrm{( \cdots \cdots )} \mathrm{GCE,} \mathrm{(-----)} \mathrm{fMWCNT/GCE,} \mathrm{(----)} \mathrm{[BMIM]PF6/GCE} \mathrm{and} \mathrm{()} \mathrm{fMWCNT-}$

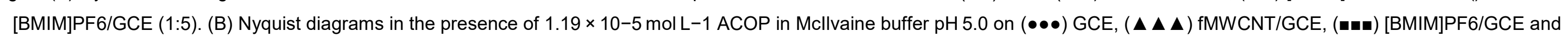

$(\bullet \bullet) \mathrm{fMWCNT}$-[BMIM]PF6/GCE (1:5) with $\mathrm{f}=40 \mathrm{kHz}$ to $10 \mathrm{mHz}, \mathrm{a}=10 \mathrm{mV}$ and Ep/2 $=+0.51 \mathrm{~V},+0.50 \mathrm{~V},+0.54 \mathrm{Ve}+0,51 \mathrm{~V}$, respectively.

No redox peak was obtained in all voltammograms in Sörensen buffer pH 5.0 in absence of ACOP indicating that all of modified surfaces were non-electroactive in the potential range studied. In the presence of $1.19 \times 10-5 \mathrm{~mol} \mathrm{~L}-1$ of ACOP a well-defined peak was obtained on different surfaces. From bare GCE, peak potentials were obtained at $0.539 \mathrm{~V}$ and $0.476 \mathrm{~V}$, with a separation $(\Delta \mathrm{Ep})$ of $63.5 \mathrm{mV}$. When fMWCNT or [BMIM]PF6 were used to modify the bare GCE, the redox pair relative to ACOP was observed only for the first modification. At fMWCNT/GCE it was detected an oxidation peak at $0.530 \mathrm{~V}$ and a reduction peak at $0.488 \mathrm{~V}$ with separation $(\Delta \mathrm{Ep})$ of $41.5 \mathrm{mV}$. For the [BMIM]PF6/GCE the oxidation peak was recorded at $0.583 \mathrm{~V}$. At [BMIM]PF6-fMWCNT/GCE (1:5) an oxidation peak was observed at $0.534 \mathrm{~V}$ and a reduction peak at $0.493 \mathrm{~V}$ with $\Delta \mathrm{Ep}$ of $41.5 \mathrm{mV}$. It could be noted that the oxidation of ACOP at [BMIM]PF6/GCE was an irreversible process under these experimental conditions, and the modification with fMWCNT exhibited a quasi-reversible process. The dispersion with fMWCNT-[BMIM]PF6 can effectively change the oxidation potential for more negative potentials when compared with fMWCNT/GCE. Moreover, the oxidation peak current of ACOP at the [BMIM]PF6-fMWCNT/GCE (1:5) was 1.61 times higher than at the bare GCE and 1.19 times higher than at the fMWCNT/GCE. Further these results indicated that the modified electrode improved the electron transfer rate on the electrode surface and exhibited larger electro-catalytic reactivity than GCE.

Electrochemical impedance spectroscopy (EIS) is a technique for further characterization of the modified electrode, which can effectively probe the electron transfer kinetics at the electrode surface. Fig. 4B presented the Nyquist diagrams obtained for $1.19 \times 10-3 \mathrm{~mol} L-1$ ACOP in Mcllvaine buffer pH 5.0 at different electrodes.

The calculated Rct values were $415.3 \Omega, 93.2 \Omega, 7140 \Omega$ and $44 \Omega$ for GCE, fMWCNT/GCE, [BMIM]PF6/GCE and fMWCNT[BMIM]PF6/GCE (1:5), respectively. These results indicated that the modification containing fMWCNT reduced considerably the Rct values compared with GCE and the modification containing only RTIL provided opposite effect. The Rct value for fMWCNT[BMIM]PF6/GCE (1:5) was 89.4\% lower than the GCE, indicating that the film enhanced the electrical conduction pathways between the electrode surface and the supporting electrolyte [31,32].

\subsection{Effect of the scan rate}


The voltammetric profiles for $1.19 \times 10-5 \mathrm{~mol} \mathrm{L-1}$ ACOP in Mcllvaine buffer pH 5.0 on the fMWCNT-[BMIM]PF6/GCE (1:5) at different scan rates (from 0.005 to $1.0 \mathrm{~V} \mathrm{~s}-1$ ) were investigated. The dependence of peak current on square root of the scan rates was non-linear. However, the values of peak current increased linearly with the value of the scan rate, and the regression equation can be expressed

as follow: Ipa $(\mathrm{A})=-1.04 \times 10-7 \pm 1.6 \times 10-9+3.42 \times 10-8 \pm 2.1 \times 10-11 \quad \mathrm{~V} \quad(\mathrm{mVs}-1) ; \quad \mathrm{r}=0.9582 \quad$ and $\quad$ Ipc $(A)=7.29 \times 10-8 \pm 6.5 \times 10-10-2.23 \times 10-8 \pm 1.9 \times 10-11 \vee(m V s-1) ; r=0.9917$. These results suggested that the electrochemical process of ACOP on the fMWCNT-[BMIM]PF6/GCE (1:5) was an adsorption-controlled feature and this result was in agreement with different systems in the literature for ACOP detection using different modified electrodes, as graphene [56], Pd/graphene oxide [53], Fe3O4-poly(diallyldimethylammonium) chloride-graphene/GCE [54], composite film containing reduced graphene oxide and poly(3,4ethylenedioxythiophene) [57] and MWCNT-cetyltrimethyl ammonium bromide [58]. This conclusion was confirmed by linear dependence between $\log (\mathrm{Ip})$ and $\log (\mathrm{v})$ represented by equation $\log (\mathrm{Ipa} / \mathrm{A})=-7.52 \pm 1.97 \times 10-3+1.02 \pm 7.08 \times 10-4 \log (\mathrm{v} / \mathrm{mV} \mathrm{s}-1) ; \mathrm{r}=0.9969$ and $\log (-\mathrm{lpc} / \mathrm{A})=-7.96 \pm 1.05 \times 10-3+1.13 \pm 5.92 \times 10-4 \log (\mathrm{v} / \mathrm{mV} \mathrm{s}-1) ; r=0.9976$. According these equations the slopes were close to 1.0 , as expected value for a reaction with adsorbed species [59].

\subsection{Determination of ACOP using fMWCNT-[BMIM]PF6/GCE by SWV}

The ACOP sensing using the fMWCNT-[BMIM]PF6/GCE (1:5) was developed by SWV technique. All the voltammetric parameters have been optimized in $0.04 \mathrm{~mol} L-1$ Mcllvaine buffer $\mathrm{pH} 5.0$ solution in the presence of $1.19 \times 10-5 \mathrm{~mol} L-1 \mathrm{ACOP}$, such that: the $10 \mathrm{~s}-1 \leq \mathrm{f} \leq 100 \mathrm{~s}-1,10 \mathrm{mV} \leq \mathrm{a} \leq 100 \mathrm{mV}$ and $1 \mathrm{mV} \leq \Delta \mathrm{Es} \leq 5 \mathrm{mV}$.

In the optimization of frequency for ACOP on fMWCNT-[BMIM]PF6/GCE (1:5) a characteristic of quasi-reversible redox reaction could be observed when the pulse frequency was increased due to the linear dependence between $I p \times f$ and $I p \times f 1 / 2$ within the following range $(5-50 s-1)$. The kinetic constants (ks) were estimated using the relation: $k s=k m a x \cdot f m a x$, where kmax is the theoretically calculated critical kinetic parameter. A maximum at $f=30 s^{-1}(f m a x=30 s-1)$ was exhibited in the analysis of the peak currents and the corresponding frequencies plotted as a function of frequency. The responses of quasi-irreversible electrode processes are characterized according to SWV criteria [28] by a "quasi-reversible maximum". Considering the a value as unknown and kmax value as $0.49 \pm 0.12$, which applies in the range of $0.2 \leq \alpha \leq 0.8$ [28]. Therefore, the ks value with the optimized experimental parameters used was determined to be $14.7 \mathrm{~s}-1 \pm 3.6 \mathrm{~s}-1$. This value is close to the values previously reported in the literature for similar electrodes $[29,43]$.

Based on the dependence between $\mathrm{kmax}$ and $\mathrm{f}$, it was possible to analyze the occurrence of adsorption of reactants and/or products on the working electrode surface using the relation: $\log k \max \times(2 f)-1=0.010$. For this system, the calculated value was 0.019 [28,60]. Thus, it was possible to conclude that there occurs adsorption of reagents on the electrode surface, because the calculated value was relatively close to the theoretical value (0.010). This diagnosis is in agreement with the voltammetric results obtained in this study.

For the ACOP electrooxidation on fMWCNT-[BMIM]PF6/GCE (1:5) a linear dependence was observed between peak current and amplitude in the range from 5 to $100 \mathrm{mV}$. The optimized value was $25 \mathrm{mV}$, due the dependence between Ip and a was linear only when $a=50 / n[28,60]$. For $\Delta E s$, no linear relation could be seen between values of Ip and $\Delta E s$. Hence, the value of $\Delta E s=2 \mathrm{mV}$ was adopted.

Under the optimized experimental conditions, the analytical curve for ACOP was constructed in triplicate using the fMWCNT[BMIM]PF6/GCE. Fig. 5 shows the SWV recorded for different [ACOP] and the respective analytical curve. The oxidation peak current was proportional to $[A C O P]$ in the range from 0.3 to $3.0 \mu \mathrm{mol} L-1$ following the linear regression equation $\mathrm{Ip}(\mathrm{A})=-1.31 \times 10-7+2.09$ [ACOP] (mol L-1) $(r=0.9933)$, with the limit of detection (LOD) equals to $67.3 \mathrm{nmol} L-1$. 


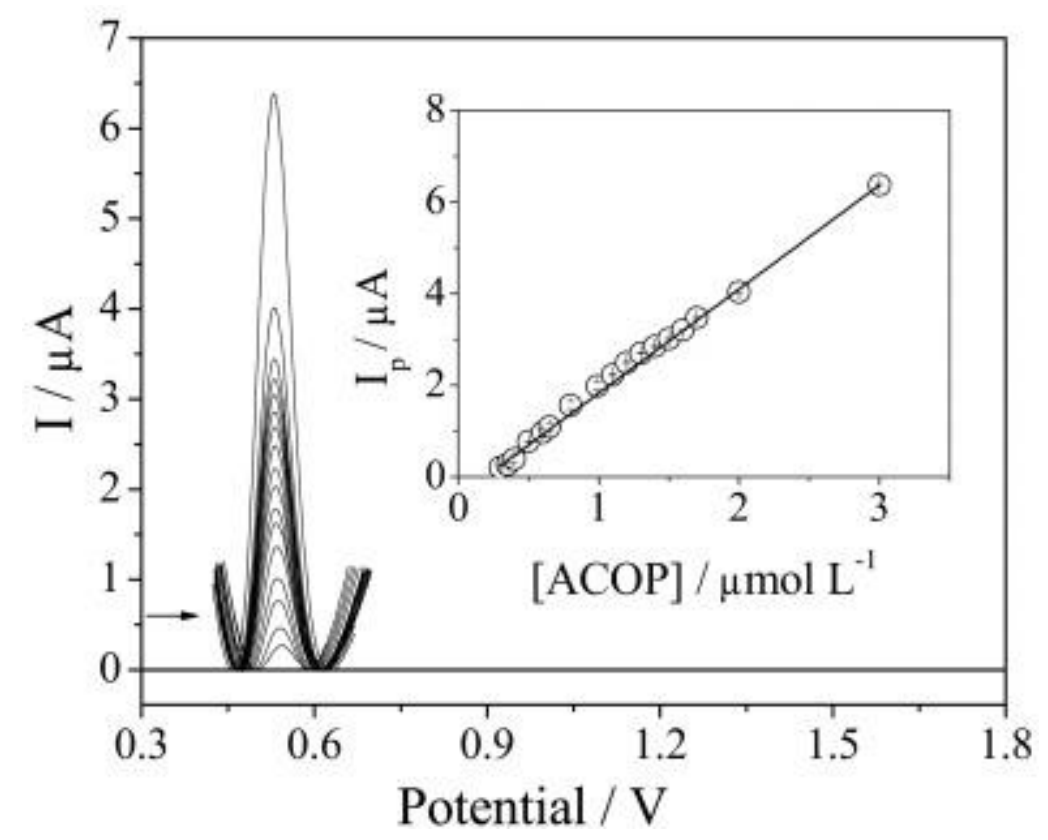

Fig. 5. Square-wave voltammograms for ACOP determination in Mcllvaine buffer $p H 5.0$ on fMWCNT-[BMIM]PF6/GCE $(1: 5)$ with $\mathrm{f}=30 \mathrm{~s}-1, \mathrm{a}=25 \mathrm{mV}$ and $\Delta \mathrm{Es}=2 \mathrm{mV}$, and concentrations in the range of 0.3 to $3.0 \mu \mathrm{mol} L-1$. Inset: Average peak currents obtained from three analytical curves.

The LOD and limit of quantification (LOQ) for ACOP were obtained by using the procedure recommended by International Union of Pure and Applied Chemistry (IUPAC) [61]. Reproducibility (inter-day) and repeatability (intra-day) studies were performed, with relative standard deviation (RSD) values indicating that the procedure showed good repeatability and reproducibility, and could be successfully employed for analytical purposes. All figures of merit can be seen in Table 1.

Table 1. Analytical parameters for the ACOP determination by SWV methodology.

\begin{tabular}{|c|c|}
\hline Parameter & {$[\mathrm{BMIM}] \mathrm{PF}_{c}$} \\
\hline Linearity range $/ \mu \mathrm{molL}^{-1}$ & 0.3 to 3.0 \\
\hline Intercept $/ \mu \mathrm{A}$ & -0.131 \\
\hline Slope/A mol ${ }^{-1} \mathrm{~L}$ & 2.09 \\
\hline Confidence interval of intercept & \pm 0.116 \\
\hline Confidence interval of the slope & \pm 0.20 \\
\hline Correlation coefficient & 0.9933 \\
\hline $\mathrm{SD}$ of the intercept/nA & 46.9 \\
\hline LOD/nmol L ${ }^{-1}$ & 67.3 \\
\hline $\mathrm{LOQ} / \mathrm{nmol} \mathrm{L}^{-1}$ & 224 \\
\hline \%RSD interday & $2.56(n=7)$ \\
\hline \%RSD intraday & $2.34(n=5)$ \\
\hline
\end{tabular}

The analytical performance of fMWCNT-[BMIM]PF6/GCE was compared with some recently published reports, Table 2. The linear range obtained for the proposed sensor is similar of others reported modified electrodes. The LOD obtained in this work is higher than the modified electrode with graphene [56,63] and Nano-TiO2 [48], however the proposed sensor exhibit lower LOD value than other modified electrodes which could confirm that fMWCNT-[BMIM]PF6/GCE have high electrocatalytic and surface effects. Therefore, the fMWCNT[BMIM]PF6/GCE showed sensitivity up to 40 times higher when compared to ACOP sensors modified with metallic nanoparticles [62] for the determination of ACOP. Additionally, the LOD and LOQ values calculated by the proposed procedure presented values lower than data calculated from the use of the UV-Vis spectrophotometry (procedure recommended by United State Pharmacopoeia) previously published [29]. Furthermore, it is emphasized that the analytical parameters obtained in this work were sufficient to determine ACOP in tablets (Tylenol® and Tylenol®DC). 
Table 2. Analytical characteristics for determination of acetaminophen at several reported

modified electrodes.

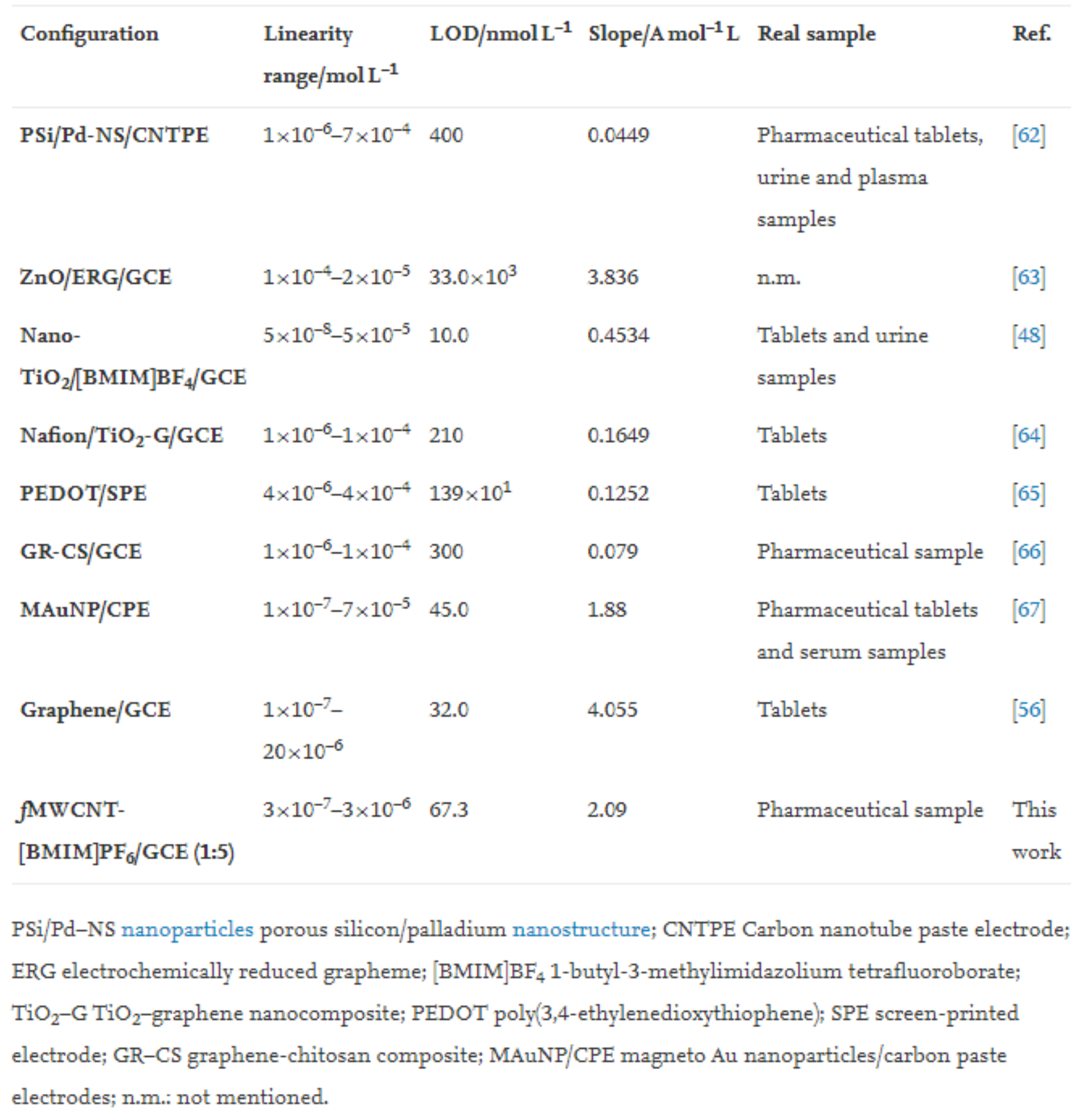

\subsection{Determination of ACOP in tablets}

In order to determine ACOP in two different commercial formulations the standard addition method was used. These analyses were performed in triplicate and the results obtained are shown in Table 3. The ACOP quantification of these samples was also performed by UV-Vis spectrophotometry at $\lambda=257 \mathrm{~nm}$, for comparison and for determination of accuracy of methodology proposed. The calculated recoveries of ACOP using fMWCNT-[BMIM]PF6/GCE (1:5) by SWV were $82.84 \%$ and $94.75 \%$ and by UV-Vis $\lambda=257 \mathrm{~nm}$ were $93.64 \%$ and $108.97 \%$ for Tylenol $\circledast$ and Tylenol $\Theta D C$, respectively. Despite the presence of other electrochemically active compounds such as caffeine, all values obtained are within the acceptable linear range recovery percentages as a function of the analyte concentration [68].

$$
\begin{aligned}
& \text { Table 3. ACOP recovered concentrations using } f \text { MWCNT-[BMIM] } \mathrm{PF}_{6} / \mathrm{GCE}(1: 5) \text { by SWV } \\
& \text { methodology and UV-Vis } \lambda_{=257 \mathrm{~nm}} \text { in pharmaceutical formulations. }
\end{aligned}
$$

\begin{tabular}{|c|c|c|c|c|}
\hline \multirow[b]{2}{*}{ Parameter } & \multicolumn{2}{|c|}{$\left[\mathrm{BMIM} \mathrm{PF}_{6}-\mathrm{fMWCNT} / \mathrm{GCE}(1: 5)\right.$} & \multicolumn{2}{|l|}{ UV-Vis $\lambda_{\lambda=257 \mathrm{~nm}}$} \\
\hline & Tylenol@500 mg & TylenoløDC & Tylenolø500 mg & TylenoløDC \\
\hline$[\mathrm{ACOP}]_{\mathrm{add}}\left(\mathrm{mol} \mathrm{L}^{-1}\right)$ & $1.09 \times 10^{-6}$ & $1.09 \times 10^{-6}$ & $1.09 \times 10^{-6}$ & $1.09 \times 10^{-6}$ \\
\hline$[\mathrm{ACOP}]_{\text {found }}\left(\mathrm{mol} \mathrm{L}^{-1}\right)$ & $9.03 \times 10^{-7}$ & $1.01 \times 10^{-6}$ & $1.03 \times 10^{-6}$ & $1.18 \times 10^{-6}$ \\
\hline Confidence interval (\%) & $\pm 2.02 \times 10^{-8}$ & $\pm 3.32 \times 10^{-8}$ & $\pm 9.10 \times 10^{-8}$ & $\pm 9.10 \times 10^{-8}$ \\
\hline Recovery (\%) & 82.84 & 94.75 & 93.64 & 108.97 \\
\hline RSD (\%) & 2.2 & 3.0 & 3.3 & 3.4 \\
\hline BIAS (\%) & -17.2 & -5.3 & -6.4 & 9.0 \\
\hline
\end{tabular}

To evaluate the precision and accuracy of the two methodologies developed, F-test and Student's t-test were carried out with confidence limit of $95 \%$. For the F-test it was deliberated as a null hypothesis that the variances of the methods are identical and consequently have 
the same precision. Though in the paired t-test was adopted as the null hypothesis so that no there is considerable change in the accuracy of both methods [69]. The F-test was calculated and the F values were always lower than 0.12 indicating that the proposed methodology is more precise than the UV-Vis methodology, since the F critical value is 19.00 [69]. Although the calculated values of $t$ (4.3) was the same of the tabulated value (4.3) implying that the null hypothesis is true. Thus, the accuracy of the method was statistically similar to the standard methodology adopted by the pharmacopeia. It means the sensor developed is suitable for ACOP determination in pharmaceuticals formulations with high sensitivity and precision.

\section{Conclusions}

A quantitative electroanalytical methodology has been developed for ACOP determination using the fMWCNT-[BMIM]PF6/GCE, based on the enhanced electrochemical reactivity when compared with GCE bare, [BMIM]PF6/GCE and fMWCNT/GCE. The electrooxidation of ACOP at the fMWCNT-[BMIM]PF6/GCE (1:5) was an adsorption-controlled process involving two-electrons and two-protons. The developed sensor has shown to be an excellent electron transfer promoter $(k s=14.7 s-1 \pm 3.6 s-1)$ and had some advantages, such as simplicity and renewability, high stability, appropriate linear range and low LOD (67.3 nmol L-1). The proposed methodology was applied with success in the determination of ACOP in commercial pharmaceutical formulations and the recovery percentages (82.84\% and $94.75 \%)$ which were satisfactory in the analytical procedures.

\section{Acknowledgements}

The authors gratefully acknowledge funding provided by the following Brazilian agencies: CNPq-INCT (Proc. 573925/2008-9 and 573548/2008-0), CAPES/Funcap (2133/2012/Proc. 23038.007973/2012-90), CNPq-PVE (Proc. 400223/2014-7 and 303596/2014-7), PRONEX/FUNCAP (Proc. PR2-0101-00030.01.00/15) and CNPq (Proc. 302801/2014-6). R.N. Gomes thanks CAPES and C.P. Sousa thanks CAPES-PNPD for their grants. The authors also are grateful to the Central Analítica-UFC/CT-INFRA/MCTI-SISNANO/PróEquipamentos CAPES for technical support and Prof. Pierre Basílio Almeida Fechine and MsC. Davino Machado Andrade Neto for Zeta potential analysis.

\section{References}

[1] H. Jaeschke, Y. Xie, M.R. McGill

Acetaminophen-induced liver injury: from animal models to humans

J. Clin. Transl. Hepatol., 2 (2014), pp. 153-161

[2] M. Mazer, J. Perrone

Acetaminophen-induced nephrotoxicity: pathophysiology, clinical manifestations, and management

J. Med. Toxicol., 4 (2008), pp. 2-6

[3] A. Cernat, M. Tersiş, R. Săndulescu, F. Bedioui, A. Cristea, C. Cristea

Electrochemical sensors based on carbon nanomaterials for acetaminophen detection: a review

Anal. Chim. Acta, 886 (2015), pp. 15-28

[4] S.F. Cook, A.D. King, J.N. van der Anker, D.G. Wilkins

Simultaneous quantification of acetaminophen and five acetaminophen metabolites in human plasma and urine by high-performance liquid chromatography-electrospray ionization-tandem mass spectrometry: method validation and application to a neonatal pharmacokinetic study

J. Chromatogr. B, 1007 (2015), pp. 30-42 
[5] E. Souri, S.A.M. Nasab, M. Amanlou, M.B. Tehrani

Development and validation of a rapid spectrophotometric method for simultaneous determination of acetaminophen, ibuprofen and caffeine

J. Anal. Chem., 70 (2015), pp. 333-338

[6] M.A. Mallah, S.T.H. Sherazi, M.I. Bhanger, S.A. Mahesar, M.A. Bajeer

A rapid Fourier-transform infrared (FTIR) spectroscopic method for direct quantification of paracetamol content in solid pharmaceutical formulations

Spectrochim. Acta A, 141 (2015), pp. 64-70

[7] A.M. Santos, F.C. Vicentini, L.C.S. Figueiredo-Filho, P.B. Deroco, O. Fatibello-Filho

Flow injection simultaneous determination of acetaminophen and tramadol in pharmaceutical and biological samples using multiple pulse amperometric detection with a boron-doped diamond electrode

Diam. Relat. Mater., 60 (2015), pp. 1-8

[8] A. Klimek-Turek, M. Sikora, M. Rybicki, T.H. Dzido

Frontally eluted components procedure with thin layer chromatography as a mode of sample preparation for high performance liquid chromatography quantitation of acetaminophen in biological matrix

J. Chromatogr. A, 1436 (2016), pp. 19-27

[9] M. Wesoly, X. Cetó, D. del Valle, P. Ciosek, W. Wróblewski

Quantitative analysis of active pharmaceutical ingredients (APIs) using a potentiometric electronic tongue in a SIA flow system Electroanalysis, 28 (2016), pp. 626-632

[10] M. Esterhuizen-Londt, K. Schwartz, E. Balsano, S. Kühn, S. Pflugmacher

LC-MS/MS method development for quantitative analysis of acetaminophen uptake by the aquatic fungus Mucor hiemalis

Ecotox. Environ. Safe., 128 (2016), pp. 230-235

[11] I. Pugajeva, J. Rusko, I. Perkons, E. Lundanes, V. Bartkevics

Determination of pharmaceutical residues in wastewater using high performance liquid chromatography coupled to quadrupole-Orbitrap mass spectrometry

J. Pharmaceut. Biomed., 133 (2017), pp. 64-74

[12] A.K. Baytak, T. Teker, S. Duzmen, M. Aslanoglu

A composite material based on nanoparticles of yttrium (III) oxide for the selective and sensitive electrochemical determination of acetaminophen

Mater. Sci. Eng. C (2016), pp. 278-284

[13] H. Karimi-Maleh, M.R. Ganjali, P. Norouzi, A. Bananezhad 
Amplified nanostructure electrochemical sensor for simultaneous determination of captopril, acetaminophen, tyrosine and hydrochlorothiazide

Mater. Sci. Eng. C, 73 (2017), pp. 472-477

[14] C.P. Sousa, M.A. Salvador, P. Homem-de-Mello, F.W.P. Ribeiro, P. de Lima-Neto, A.N. Correia

Computational modeling of functionalized multi-walled carbon nanotubes dispersed in polyethylenimine for electrochemical sensing of acetaminophen

Sensors Actuators B Chem., 246 (2017), pp. 969-978

[15] A.U. Alam, Y. Qin, M.M.R. Howlader, N.-X. Hu, M.J. Deen

Electrochemical sensing of acetaminophen using multi-walled carbon nanotube and $\beta$-cyclodextrin

Sensors Actuators B Chem., 254 (2018), pp. 896-909

[16] M. Opallo, A. Lesniewski

A review on electrodes modified with ionic liquids

J. Electroanal. Chem., 656 (2011), pp. 2-16

[17] R.T. Kachoosangi, M.M. Musameh, I. Abu-Yousef, J.M. Yousef, S.M. Kanan, L. Xiao, S.G. Davies, A. Russell, R.G. Compton Carbon nanotube-ionic liquid composite sensors and biosensors

Anal. Chem., 81 (2009), pp. 435-442

[18] A. Abo-Hamad, M.A. AlSaadi, M. Hayyan, I. Juneidi, M.A. Hashim

Ionic liquid-carbon nanomaterial hybrids for electrochemical sensor applications: a review

Electrochim. Acta, 193 (2016), pp. 321-343

[19] Q. Yan, F. Zhao, G. Li, B. Zeng

Voltammetric determination of uric acid with a glassy carbon electrode coated by paste of multiwalled carbon nanotubes and ionic liquid Electroanalysis, 18 (2006), pp. 1075-1080

[20] H. Tao, W. Wei, X. Zeng, X. Liu, X. Zhang, Y. Zhang

Electrocatalytic oxidation and determination of estradiol using an electrode modified with carbon nanotubes and an ionic liquid Microchim. Acta, 166 (2009), pp. 53-59

[21] A.-M. Gurban, L. Rotariu, M. Baibarac, I. Baltog, C. Bala

Sensitive detection of endocrine disrupters using ionic liquid - single walled carbon nanotubes modified screen-printed based biosensors Talanta, 85 (2011), pp. 2007-2013 
[22] J. Jang, D.-H. Kim, W.-Y. Lee

Electrochemical determination of bisphenol A by a single-walled carbon nanotube composite glassy carbon electrode

Anal. Lett., 49 (2016), pp. 2018-2030

[23] M. Wang, Y. Gao, J. Zhang, J. Zhao

Highly dispersed carbon nanotube in new ionic liquid-graphene oxides aqueous dispersions for ultrasensitive dopamine detection

Electrochim. Acta, 155 (2015), pp. 236-243

[24] J. Yang, Q. Wang, M. Zhang, S. Zhang, L. Zhang

An electrochemical fungicide pyrimethanil sensor based on carbon nanotubes/ionic-liquid construction modified electrode

Food Chem., 187 (2015), pp. 1-6

[25] H. Ghadimi, R.M.A. Tehrani, A.S.M. Ali, N. Mohamed, S. Ab Ghani

Sensitive voltammetric determination of paracetamol by poly(4-vinylpyridine)/multiwalled carbon nanotubes modified glassy carbon electrode

Anal. Chim. Acta, 765 (2013), pp. 70-76

[26] Z. Wang, M.D. Shirley, S.T. Meikle, R.L.D. Whitby, S.V. Mikhalovsky

The surface acidity of acid oxidised multi-walled carbon nanotubes and the influence of in-situ generated fulvic acids on their stability in aqueous dispersions

Carbon, 47 (2009), pp. 73-79

[27] K.A. Wepasnick, B.A. Smith, K.E. Schrote, H.K. Wilson, S.R. Diegelmann, D.H. Fairbrother

Surface and structural characterization of multi-walled carbon nanotubes following different oxidative treatments

Carbon, 49 (2011), pp. 24-36

[28] V. Mirceski, S. Komorsky-Lovric, M. Lovric

Square-Wave Voltammetry: Theory and Application

Springer Science \& Business Media, Berlin Heidelberg (2007)

[29] L.F. de Holanda, F.W.P. Ribeiro, C.P. Sousa, P.N. da Silva Casciano, P. de Lima-Neto, A.N. Correia

Multi-walled carbon nanotubes-cobalt phthalocyanine modified electrode for electroanalytical determination of acetaminophen

J. Electroanal. Chem., 772 (2016), pp. 9-16

[30] Brasil

Farmacopeia Brasileira

(5th ed.), Agência Nacional de Vigilância Sanitária, Brasília (2010)

Part 2 
[31] W. Guo, Y. Liu, X. Meng, M. Pei, W. Jinping, L. Wang

A novel signal amplification strategy of an electrochemical immunosensor for human chorionic gonadotropin, based on nanocomposites of multi-walled carbon nanotubes-ionic liquid and nanoporous $\mathrm{Pd}$

RSC Adv., 4 (2014), pp. 57773-57780

[32] M.L. Polo-Luque, B.M. Simonet, M. Valcarcel

Functionalization and dispersion of carbon nanotubes in ionic liquids

TrAC Trends Anal. Chem., 47 (2013), pp. 99-110

[33] L. Jiang, L. Gao

Modified carbon nanotubes: an effective way to selective attachment of gold nanoparticles

Carbon, 41 (2003), pp. 2923-2929

[34] Q. Liao, J. Sun, L. Gao

The adsorption of resorcinol from water using multi-walled carbon nanotubes

Colloids Surf. A, 312 (2008), pp. 160-165

[35] R. Li, X. Wang, Z. Ji, B. Sun, H. Zhang, C.H. Chang, et al.

Surface charge and cellular processing of covalently functionalized multiwall carbon nanotubes determine pulmonary toxicity ACS Nano, 7 (2013), pp. 2352-2368

[36] X. Cao, L. Tao, S. Wen, W. Hou, X. Shi

Hyaluronic acid-modified multiwalled carbon nanotubes for targeted delivery of doxorubicin into cancer cells

Carbohydr. Res., 405 (2015), pp. 70-77

[37] H. Li, J. Chen, S. Han, W. Niu, X. Liu, G. Xu

Electrochemiluminescence from tris(2,2'-bipyridyl)ruthenium(II)-graphene-nafion modified electrode

Talanta, 79 (2009), pp. 165-170

[38] J. Liu, W. Zhang, Y. Li, L. Yang, B. Ye

A highly sensitive sensor for synephrine detection based on multi-walled carbon nanotubes modified glass carbon electrodes Anal. Methods, 5 (2013), pp. 5317-5323

[39] Z. Ye, L. Wang, J. Wen

A simple and sensitive method for determination of norfloxacin in pharmaceutical preparations

Braz. J. Pharm. Sci., 51 (2015), pp. 429-437 
[40] H. Zeinali, H. Bagheri, Z. Monsef-Khoshhesab, H. Khoshsafar, A. Hajian

Nanomolar simultaneous determination of tryptophan and melatonin by a new ionic liquid carbon paste electrode modified with SnO2Co304@ rGO nanocomposite

Mater. Sci. Eng. C, 71 (2017), pp. 386-394

[41] F.W.P. Ribeiro, F.W.S. Lucas, L.H. Mascaro, S. Morais, P.N.S. Casciano, P. De Lima-Neto, A.N. Correia

Electroanalysis of formetanate hydrochloride by a cobalt phthalocyanine functionalized multiwalled carbon nanotubes modified electrode: characterization and pplication in fruits

Electrochim. Acta, 194 (2016), pp. 187-198

[42] D.J. Miner, J.R. Rice, R.M. Riggin, P.T. Kissinger

Voltammetry of acetaminophen and its metabolites

Anal. Chem., 53 (1981), pp. 2258-2263

[43] P. Fanjul-Bolado, P. Jose Lamas-Ardisana, D. Hernandez-Santos, A. Costa-Garcia

Electrochemical study and flow injection analysis of paracetamol in pharmaceutical formulations based on screen-printed electrodes and carbon nanotubes

Anal. Chim. Acta, 638 (2009), pp. 133-138

[44] D. Nematollahi, H. Shayani-Jam, M. Alimoradi, S. Niroomand

Electrochemical oxidation of acetaminophen in aqueous solutions: kinetic evaluation of hydrolysis, hydroxylation and dimerization processes

Electrochim. Acta, 54 (2009), pp. 7407-7415

[45] Y. Teng, L. Fan, Y. Dai, M. Zhong, X. Lu, X. Kan

Electrochemical sensor for paracetamol recognition and detection based on catalytic and imprinted composite film

Biosens. Bioelectron., 71 (2015), pp. 137-142

[46] Y. El Bouabi, A. Farahi, N. Labjar, S. El Hajjaji, M. Bakasse, M.A. El Mhammedi

Square wave voltammetric determination of paracetamol at chitosan modified carbon paste electrode: application in natural water samples, commercial tablets and human urines

Mater. Sci. Eng. C, 58 (2016), pp. 70-77

[47] X. ShangGuan, H. Zhang, J. Zheng

Electrochemical behavior and differential pulse voltammetric determination of paracetamol at a carbon ionic liquid electrode

Anal. Bioanal. Chem., 391 (2008), pp. 1049-1055 
[48] B. Wang, Y. Li, X. Qin, G. Zhan, M. Ma, C. Li

Electrochemical fabrication of $\mathrm{TiO} 2$ nanoparticles/

[BMIM] BF4 ionic liquid hybrid film electrode and its application in determination of $p$-acetaminophen

Mater. Sci. Eng. C, 32 (2012), pp. 2280-2285

[49] C. Zhao, B. Ren, Y. Song, J. Zhang, L. Wei, S. Chen, S. Zhang

Immobilization and molecular rearrangement of ionic liquids on the surface of carbon nanotubes

RSC Adv., 4 (2014), pp. 16267-16273

[50] X. Qin, W. Guo, H. Yu, J. Zhao, M. Pei

A novel electrochemical aptasensor based on MWCNTs-

[BMIM]PF6 and amino functionalized graphene nanocomposite films for determination of kanamycin

Anal. Methods, 7 (2015), pp. 5419-5427

[51] A.J.F. Bard, L. R.

Electrochemical Methods: Fundamentals and Applications

(2nd ed.), Wiley, New York (2001)

[52] A. Kutluay, M. Aslanoglu

Modification of electrodes using conductive porous layers to confer selectivity for the voltammetric detection of paracetamol in the presence of ascorbic acid, dopamine and uric acid

Sens. Actuator B-Chem., 185 (2013), pp. 398-404

[53] J. Li, J. Liu, G. Tan, J. Jiang, S. Peng, M. Deng, D. Qian, Y. Feng, Y. Liu

High-sensitivity paracetamol sensor based on $\mathrm{Pd} /$ graphene oxide nanocomposite as an enhanced electrochemical sensing platform

Biosens. Bioelectron., 54 (2014), pp. 468-475

[54] D. Lu, Y. Zhang, L. Wang, S. Lin, C. Wang, X. Chen

Sensitive detection of acetaminophen based on $\mathrm{Fe} 3 \mathrm{O} 4$ nanoparticles-coated poly(diallyldimethylammonium chloride)-functionalized graphene nanocomposite film

Talanta, 88 (2012), pp. 181-186

[55] B. Devadas, H.-T. Yeh, S.-M. Chen, S. Piraman

Electrochemical preparation of yttrium hexacyanoferrate on reduced graphene oxide and its application to analgesic drug sensor

Electroanalysis, 26 (2014), pp. 1712-1720 
[56] X. Kang, J. Wang, H. Wu, J. Liu, I.A. Aksay, Y. Lin

A graphene-based electrochemical sensor for sensitive detection of paracetamol

Talanta, 81 (2010), pp. 754-759

[57] T.-Y. Huang, C.-W. Kung, H.-Y. Wei, K.M. Boopathi, C.-W. Chu, K.-C. Ho

A high performance electrochemical sensor for acetaminophen based on a rGO-PEDOT nanotube composite modified electrode

J. Mater. Chem. A, 2 (2014), pp. 7229-7237

[58] J.I. Gowda, D.G. Gunjiganvi, N.B. Sunagar, M.N. Bhat, S.T. Nandibewoor

MWCNT-CTAB modified glassy carbon electrode as a sensor for the determination of paracetamol

RSC Adv., 5 (2015), pp. 49043-49045

[59] K.D. Gosser Jr.

Cyclic Voltammetry: Simulation and Analysis of Reaction Mechanism

UCH, publishers, New York (1993)

[60] A.N.D. Dantas, D. De Souza, J.E.S. de Lima, P. de Lima-Neto, A.N. Correia

Voltammetric determination of ketoconazole using a polished silver solid amalgam electrode

Electrochim. Acta, 55 (2010), pp. 9083-9089

[61] J. Mocak, A. Bond, S. Mitchell, G. Scollary

A statistical overview of standard (IUPAC and ACS) and new procedures for determining the limits of detection and quantification: application to voltammetric and stripping techniques (technical report)

Pure Appl. Chem., 69 (1997), pp. 297-328

[62] A.A. Ensafi, N. Ahmadi, B. Rezaei, M.M. Abarghoui

A new electrochemical sensor for the simultaneous determination of acetaminophen and codeine based on porous silicon/palladium nanostructure

Talanta, 134 (2015), pp. 745-753

[63] L. Jiang, S. Gu, Y. Ding, F. Jiang, Z. Zhang

Facile and novel electrochemical preparation of a graphene-transition metal oxide nanocomposite for ultrasensitive electrochemical sensing of acetaminophen and phenacetin

Nano, 6 (2014), pp. 207-214

[64] Y. Fan, J.-H. Liu, H.-T. Lu, Q. Zhang

Electrochemical behavior and voltammetric determination of paracetamol on nafion/TiO2-graphene modified glassy carbon electrode Colloids Surf., B, 85 (2011), pp. 289-292 
[65] W.-Y. Su, S.-H. Cheng

Electrochemical oxidation and sensitive determination of acetaminophen in pharmaceuticals at poly(3,4-ethylenedioxythiophene)modified screen-printed electrodes

Electroanalysis, 22 (2010), pp. 707-714

[66] M. Zheng, F. Gao, Q. Wang, X. Cai, S. Jiang, L. Huang, F. Gao

Electrocatalytical oxidation and sensitive determination of acetaminophen on glassy carbon electrode modified with graphene-chitosan composite

Mater. Sci. Eng. C, 33 (2013), pp. 1514-1520

[67] E. Haghshenas, T. Madrakian, A. Afkhami

A novel electrochemical sensor based on magneto au nanoparticles/carbon paste electrode for voltammetric determination of acetaminophen in real samples

Mater. Sci. Eng. C, 57 (2015), pp. 205-214

[68] I. Taverniers, M. De Loose, E. Van Bockstaele

Trends in quality in the analytical laboratory. II. Analytical method validation and quality assurance

TrAC Trends Anal. Chem., 23 (2004), pp. 535-552

[69] J.N. Miller, J.C. Miller

Statistics and Chemometrics for Analytical Chemistry

Pearson Prentice Hall, United Kingdom (2005) 